ARTICLE

\title{
Wireless optogenetics protects against obesity via stimulation of non-canonical fat thermogenesis
}

\author{
Kazuki Tajima (10) 1,2,3,8, Kenji Ikeda1,2,3,7,8, Yuji Tanabe4, Ella A. Thomson (10 4, Takeshi Yoneshiro ${ }^{1,2,3}$, \\ Yasuo Oguri ${ }^{1,2,3}$, Marc D. Ferro ${ }^{5}$, Ada S. Y. Poon (10 ${ }^{4,6 凶} \&$ Shingo Kajimura (i) $1,2,3 凶$
}

Cold stimuli and the subsequent activation of $\beta$-adrenergic receptor ( $\beta$-AR) potently stimulate adipose tissue thermogenesis and increase whole-body energy expenditure. However, systemic activation of the $\beta 3-A R$ pathway inevitably increases blood pressure, a significant risk factor for cardiovascular disease, and, thus, limits its application for the treatment of obesity. To activate fat thermogenesis under tight spatiotemporal control without external stimuli, here, we report an implantable wireless optogenetic device that bypasses the $\beta$-AR pathway and triggers $\mathrm{Ca}^{2+}$ cycling selectively in adipocytes. The wireless optogenetics stimulation in the subcutaneous adipose tissue potently activates $\mathrm{Ca}^{2+}$ cycling fat thermogenesis and increases whole-body energy expenditure without cold stimuli. Significantly, the light-induced fat thermogenesis was sufficient to protect mice from diet-induced body-weight gain. The present study provides the first proof-of-concept that fat-specific cold mimetics via activating non-canonical thermogenesis protect against obesity.

\footnotetext{
${ }^{1}$ UCSF Diabetes Center, San Francisco, CA 94143, USA. ${ }^{2}$ Eli and Edythe Broad Center of Regeneration Medicine and Stem Cell Research, San Francisco, CA 94143, USA. ${ }^{3}$ Department of Cell and Tissue Biology, University of California, San Francisco, CA 94143, USA. ${ }^{4}$ Department of Electrical Engineering, Stanford University, Stanford, CA 94305, USA. ${ }^{5}$ Department of Materials Science and Engineering, Stanford University, Stanford, CA 94305, USA. ${ }^{6}$ Chan Zuckerberg Biohub, San Francisco, CA 94158, USA. ${ }^{7}$ Present address: Department of Molecular Endocrinology and Metabolism, Tokyo Medical and Dental University, 1-545, Yushima, Bunkyo-ku, Tokyo 113-8510, Japan. ${ }^{8}$ These authors contributed equally: Kazuki Tajima, Kenji Ikeda. ${ }^{凶}$ email: adapoon@stanford.edu; shingo.kajimura@ucsf.edu
} 
$\mathrm{N}$ on-shivering thermogenesis by thermogenic fat cells (brown and beige fat) plays a significant role in the regulation of whole-body energy homeostasis. Recent studies have illuminated the therapeutic potential of thermogenic fat for the treatment of metabolic disorders because impaired adipose thermogenesis is tightly associated with the development of obesity and insulin resistance, whereas activation of the thermogenic pathway potently improves metabolic health ${ }^{1,2}$.

The best-known stimulus of adipose tissue thermogenesis is cold: following cold exposure, noradrenaline (NA) released from the sympathetic nerve system (SNS) activates the $\beta 3$-adrenergic receptor $(\beta 3-A R)$ and its downstream signaling pathway, including PKA and p38MAPK, which triggers adipose tissue thermogenesis through uncoupling protein 1 (UCP1) as well as UCP1-independent mechanisms ${ }^{3-6}$. Accordingly, extensive efforts have been made to develop $\beta 3$-AR agonists as an antiobesity medication that stimulates adipose tissue thermogenesis. Consistent with the model, a selective $\beta 3$-AR agonist, mirabegron, significantly promotes adipose tissue thermogenesis and resting metabolic rate by approximately $200 \mathrm{kcal}$ per day in adult humans ${ }^{7}$. However, a major hurdle for applying $\beta 3$-AR agonists to the treatment of obesity is that, besides the poor bioavailability, pharmacological $\beta 3-\mathrm{AR}$ activation at an effective dose to achieve thermogenesis inevitably increases blood pressure as well ${ }^{8,9}$. Accordingly, identifying alternative pathways that stimulate fat thermogenesis, while avoiding cardiovascular risks, could lead to effective and safe therapeutic interventions for obesity.

The recent identification of non-canonical UCP1-independent thermogenesis may offer unique opportunities to enhance adipose tissue thermogenesis ${ }^{10,11}$. We previously reported a UCP-independent mechanism in beige fat that involves ATPdependent $\mathrm{Ca}^{2+}$ futile cycling through Sarco/endoplasmic reticulum $\mathrm{Ca}^{2+}$-ATPase2b (SERCA2b) and Ryanodine Receptor 2 $(\mathrm{RyR} 2)^{10}$. The $\mathrm{Ca}^{2+}$ cycling thermogenesis is evolutionally conserved in humans, mice, and also pigs, a mammalian species that lack a functional UCP1 protein ${ }^{10}$. Notably, enhanced $\mathrm{Ca}^{2+}$ cycling by $\mathrm{S} 107$, a chemical stabilizer for the RyR2-Calstabin interaction, potently stimulated UCP1-independent thermogenesis and protected Ucp1 null mice from hypothermia following cold exposure $^{10}$. A limitation in the study, however, was that S107 was systemically administered to mice, such that we were not able to exclude the possibility that other tissues than the adipose tissue, such as skeletal muscle, might contribute to UCP1-independent thermogenesis. Thus, adipocyte-specific manipulation of the $\mathrm{Ca}^{2+}$ cycling pathway would critically test the therapeutic potential of non-canonical fat thermogenesis for the treatment of obesity.

In this regard, optogenetics is a powerful tool for temporal and spatial manipulation of neuronal or cellular activities in vivo. The conventional optogenetics studies required fiber optic tethering and/or large head-mounted receivers, such that it limits the application to metabolic studies in general. In contrast, a recent advance in wirelessly powered optogenetics devices enabled an efficient and stable light delivery into peripheral nerves of freely behaving animals ${ }^{12}$. Accordingly, we develop a wireless optogenetics device that is implantable to the subcutaneous adipose tissue of mice. The device is distinct from the previous attempts in that it can stimulate peripheral cells (i.e., adipocytes) rather than neurons. By employing this implantable wireless device, the present study reports that light-activated $\mathrm{Ca}^{2+}$ cycling in adipocytes sufficiently stimulates non-canonical thermogenesis and protects mice against diet-induced obesity.

\section{Results}

Development of a wireless optogenetics device for adipose tissue. We previously utilized the strong localization of electromagnetic energy at low gigahertz frequencies to develop wireless optogenetics devices with dimensions on the order of a few millimeters ${ }^{12}$. However, there is very limited space between the skin and subcutaneous fat tissue to accommodate the device. Thus, we optimized the height of the device to be sub-millimeter (Fig. 1a, inset), such that they can be inserted bilaterally into the subcutaneous inguinal adipose tissue of mice (Fig. 1a and Supplementary Movie 1). The device is much smaller $\left(2 \mathrm{~mm}^{3}, 20 \mathrm{mg}\right)$ than our previously reported devices, whereas the efficiency of LED remained the same as the previous study (approximately $19 \%)$ and the power transferred to the implant at the output of the rectifier across the surface of the resonant cavity approximately varied from 1.5 to $3 \mathrm{~mW}$ (time-averaged cavity input power of $150 \mathrm{~mW}, 5 \%$ duty cycle $)^{12}$. In addition, the efficiency of the rectifier was between $20 \%$ and $60 \%$ (Supplementary Fig. 1a). This wireless optogenetic device can be implanted entirely underneath the skin, while the light source was not blocked by the antenna or other circuit components. The device consists of a tiny power-harvesting coil (2-mm diameter) with terminals connected to a receiving circuit configured with a rectifier to drive a blue micro-LED to activate channelrhodopsin 2 (ChR2) (Fig. 1b). The attenuation coefficient in adipose tissues was lower than that in the brain (adipose tissues, $\mu_{\mathrm{s}}^{\prime}=0.8 \mathrm{~mm}^{-1}$; Brain, $\left.\mu_{\mathrm{s}}^{\prime}=1.6 \mathrm{~mm}^{-1}\right)$, suggesting that the wireless LED device can stimulate ChR2-expressing cells in a broader area of adipose tissues relative to the brain (Supplementary Fig. 1b). A primary bilayer of acrylic and Parylene- $C$ was used to encapsulate the device to electrically insulate the circuitry and to resist biological degradation for chronic studies (Supplementary Fig. 1c). The implanted devices are powered and controlled using an aluminum resonant cavity with a surface lattice of hexagons ${ }^{13}$. In addition to the in vivo test setup, we also developed an in vitro setup to rapidly depolarize cultured cells that express ChR2 upon exposure to blue light. The optogenetic device was powered by a crossed-slot antenna ${ }^{14}$, and they were placed on top of a glassbottom dish (Fig. 1c).

By using these systems, we determined the optimal light pulses that stimulate intracellular $\mathrm{Ca}^{2+}$ influx with negligible heat emission from the device. To this end, we performed optogenetic stimulation in differentiated beige adipocytes expressing ChR2 with fixed $10-\mathrm{Hz}$ frequency and 1,5 , or $10 \mathrm{~ms}$ pulse widths $(1 \%$, $5 \%$, and $10 \%$ duty cycle, respectively) (Fig. 1d). For each set of pulse parameters, we also measured heat emission from the wireless device implanted into the inguinal WAT of wild-type mice (Supplementary Fig. 1d). Based on the measurements in intracellular $\mathrm{Ca}^{2+}$ influx and tissue temperature, we found that a pulse width of $5 \mathrm{~ms}$ yielded potent intracellular $\mathrm{Ca}^{2+}$ influx, whereas the same light pulses did not trigger heat emission from the device in the inguinal WAT of mice (Fig. 1e). Subsequently, we fixed the pulse width to $5 \mathrm{~ms}$ and varied the pulse frequency to 1,10 , or $20 \mathrm{~Hz}(0.5 \%, 5 \%$, and $10 \%$ duty cycle, respectively) in beige adipocytes expressing ChR2 and the inguinal WAT of wildtype mice (Fig. 1f and Supplementary Fig. 1e). These results showed that pulse width of $5 \mathrm{~ms}$ and $10-\mathrm{Hz}$ frequency (5\% duty cycle) was optimal to stimulate intracellular $\mathrm{Ca}^{2+}$ flux with negligible heat emission from the device in the adipose tissue (Fig. 1g). The light-stimulated intracellular $\mathrm{Ca}^{2+}$ influx was observed at a pulse width of $500 \mu$ s as long as the duty cycle was maintained at $5 \%$ (Supplementary Fig. 1f, g). The light-triggered intracellular $\mathrm{Ca}^{2+}$ influx is due to optogenetic activation of ChR2 because the optimized light-pulses with $10-\mathrm{Hz}$ frequency and 5ms pulse width potently increased intracellular $\mathrm{Ca}^{2+}$ influx in beige adipocytes expressing $C h R 2$, whereas no change was seen in control cells expressing an empty vector (Fig. 1h and Supplementary Movie 2). Of note, the gradual decline in intracellular $\mathrm{Ca}^{2+}$ level was owed to a relatively rapid decay of the calcium 
a

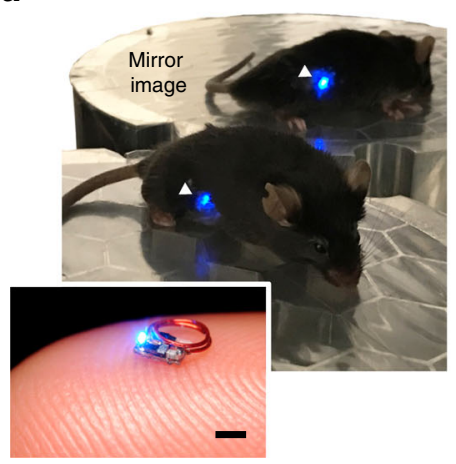

b

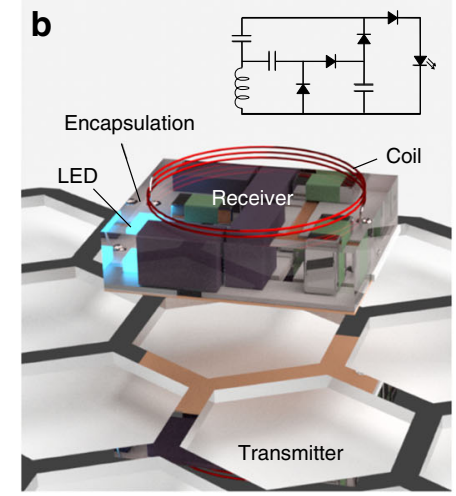

e

d

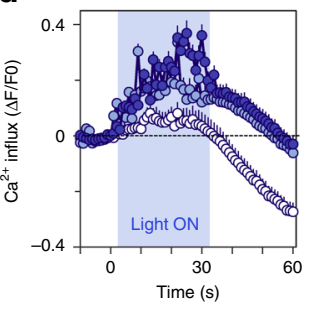

$\multimap-1 \mathrm{~ms} \quad-0-5 \mathrm{~ms} \rightarrow 10 \mathrm{~ms}$

h
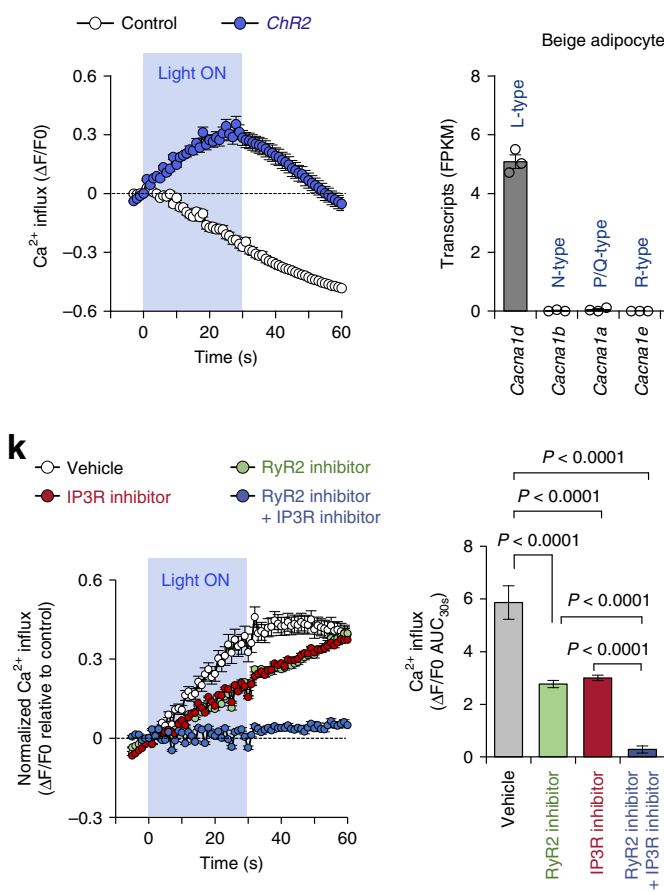

indicator Fluo-8, and thus the intercellular $\mathrm{Ca}^{2+}$ influx was normalized by the decay rate of each assay in the following experiments.

ChR2 is the light-gated, inwardly rectifying cation channel that transports protons, and both monovalent $\left(\mathrm{Na}^{+}, \mathrm{K}^{+}\right)$and divalent cations $\left(\mathrm{Ca}^{2+}, \mathrm{Mg}^{2+}\right)^{15}$. Thus, we next examined the mechanism by which light-activated membrane depolarization triggers intracellular $\mathrm{Ca}^{2+}$ influx in beige adipocytes. It is worth noting that our previous transcriptomics data ${ }^{16}$ found that L-type voltage-dependent $\mathrm{Ca}^{2+}$ channel (Cacnald) was highly expressed in isolated beige adipocytes, whereas $\mathrm{N}, \mathrm{P} / \mathrm{Q}, \mathrm{R}$, and T-type voltage-dependent $\mathrm{Ca}^{2+}$ channels were nearly absent (Fig. 1i). f
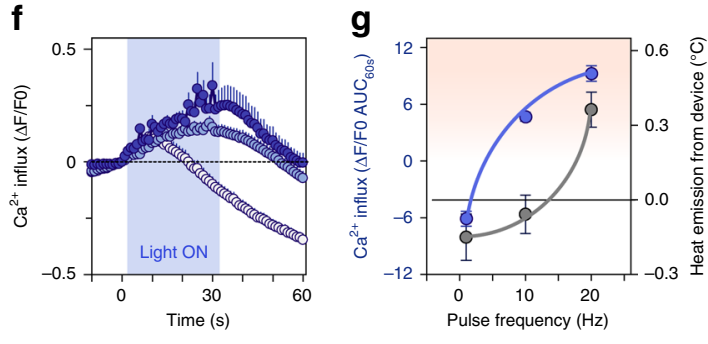

$-0-1 \mathrm{~Hz} \quad-0-10 \mathrm{~Hz} \rightarrow-20 \mathrm{~Hz}$

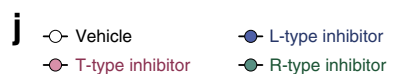
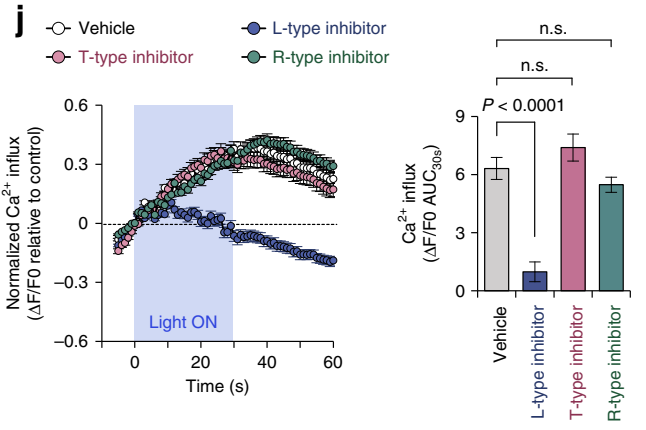

I

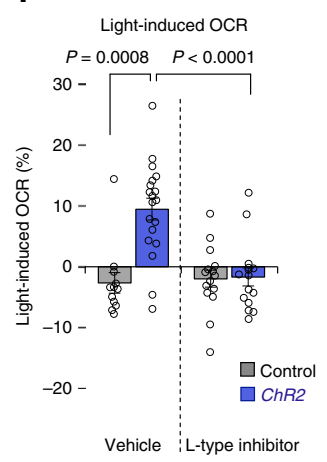

m

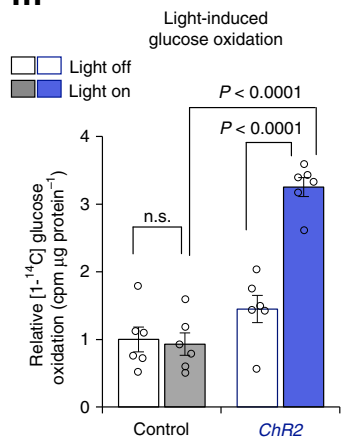

This observation caught our attention because pharmacological inhibition of L-type and R-type $\mathrm{Ca}^{2+}$ channels blunts optogenetics-induced $\mathrm{Ca}^{2+}$ flux in cultured beta-cells ${ }^{17}$. Accordingly, we treated beige adipocytes with pharmacological inhibitors of voltage-dependent $\mathrm{Ca}^{2+}$ channels and examined optogeneticsinduced intracellular $\mathrm{Ca}^{2+}$ influx. We found that pharmacological inhibition of L-type voltage-dependent $\mathrm{Ca}^{2+}$ channel by the specific inhibitor, isradipine, completely blunted the increase in intracellular $\mathrm{Ca}^{2+}$ influx following optogenetic stimulation. On the other hand, blockade of R-type and T-type voltage-dependent $\mathrm{Ca}^{2+}$ channels by SNX-482 and NNC55-0396, respectively, did not affect the optogenetics effect (Fig. 1j). These data suggest that 
Fig. 1 Wireless optogenetics implant stimulates $\mathbf{C a}^{2}+$ influx in adipocytes. a A representative image of a freely behaving mouse with the implantable wireless optogenetics device in the inguinal WAT (arrow heads). Scale bar, $1 \mathrm{~mm}$. b Three-dimensional illustration of the implantable wireless optogenetics device and the circuit diagram. $\mathbf{c}$ Schematic of optogenetic studies in cultured cells. $\mathbf{d}$ - $\mathbf{g}$ Real-time changes in intracellular $\mathrm{Ca}^{2+}$ influx following optogenetic light stimulations with indicated pulse width (d) or pulse frequency (f). d Cells stimulated with pulse width at $1 \mathrm{~ms}, n=104 ;$ at 5 or $10 \mathrm{~ms}, n=140$. f Cells stimulated with pulse frequency at 1 or $10 \mathrm{~Hz}, n=140$; at $20 \mathrm{~Hz}, n=134$. Quantification of intracellular $\mathrm{Ca}^{2+}$ influx in ChR2-expressing adipocytes stimulated with indicated pulse width (e) or pulse frequency $(\mathbf{g})$ and the heat emission from the device. The data of heat emission from the device were derived from Supplementary Fig. 1c for (e) or 1d for $(\mathbf{g})$. h Real-time changes in intracellular $\mathrm{Ca}^{2+}$ influx following optogenetic light stimulation. Vector control, $n=123$; ChR2, $n=128$. i Expression of indicated voltage-gated $\mathrm{Ca}^{2+}$ channels in isolated beige adipocytes (E-MTAB-3978). $n=3$. $\mathbf{j}$ Real-time changes (left) and quantification (right) in intracellular $\mathrm{Ca}^{2+}$ influx following optogenetic light stimulation. ChR2 with vehicle, $n=128 ;$ ChR2 with L-type inhibitor, $n=140$; ChR2 with R-type inhibitor, $n=155$; ChR2 with T-type inhibitor, $n=134$; Vector control with vehicle, $n=139$. $\mathbf{k}$ Real-time changes (left) and quantification (right) in intracellular $\mathrm{Ca}^{2+}$ influx following optogenetic light stimulation. ChR2 with vehicle, $n=105 ;$ ChR2 with RyR2 inhibitor, $n=131$; ChR2 with $I P_{3} R$ inhibitor, $n=120$; ChR2 with RyR2 inhibitor and $I_{3} R$ inhibitor, $n=140$; Vector control with vehicle, $n=140$. I Quantification of lightstimulated OCR following optogenetics light stimulation. Vector control with vehicle, $n=12$; Vector control with L-type inhibitor, $n=15 ;$ ChR2 with vehicle, $n=19$, ChR2 with L-type inhibitor, $n=15$. $\mathbf{m}$ Glucose oxidation in differentiated adipocytes expressing ChR2 or vector control with or without optogenetics light stimulation. $n=6$. Data were analyzed by one-way ANOVA (j-I) or two-way ANOVA ( $\mathbf{m})$ by Tukey's post hoc test. All Data are expressed as means \pm s.e.m. n.s. not significant.

the L-type voltage-gated $\mathrm{Ca}^{2+}$ channel mediates the light-induced membrane depolarization and triggers $\mathrm{Ca}^{2+}$ cycling in beige adipocytes.

Next, we determined the source of the intracellular $\mathrm{Ca}^{2+}$ signal in response to optogenetic stimulation of ChR2. Our previous study showed that RyR2 and inositol 1,4,5-trisphosphate receptors $\left(\mathrm{IP}_{3} \mathrm{R} 1\right.$ and $\left.\mathrm{IP}_{3} \mathrm{R} 2\right)$ are expressed in beige adipocytes, and that activation of RyR2 enhances $\mathrm{Ca}^{2+}$ cycling thermogenesis in beige fat ${ }^{10}$. Accordingly, we asked the extent to which inhibition of $\mathrm{Ca}^{2+}$ release from the ER inhibits light-induced $\mathrm{Ca}^{2+}$ flux. To this end, we treated ChR2-expressing beige adipocytes with inhibitors for RyR2 (Ryanodine) and/or $\mathrm{IP}_{3} \mathrm{R}$ (2-APB). Following ChR2 activation by blue light, we found that each inhibitor partly, but significantly, reduced intracellular $\mathrm{Ca}^{2+}$ flux. Notably, the combination of the two inhibitors completely abolished the light-induced $\mathrm{Ca}^{2+}$ signal (Fig. 1k). These data suggest that $\mathrm{Ca}^{2+}$ release from the ER via RyR2 and $\mathrm{IP}_{3} \mathrm{R}$ is required for light-activated $\mathrm{Ca}^{2+}$ cycling in beige fat.

We subsequently found that optogenetic activation of $\mathrm{Ca}^{2+}$ cycling was sufficient to activate beige fat thermogenesis without any external stimuli, such as noradrenaline (NA): the measurement of cellular oxygen consumption rate (OCR) in ChR2expressing beige adipocytes significantly increased following light stimulation. Consistent with the data that L-type voltagedependent channel blocker (isradipine) inhibited light-induced $\mathrm{Ca}^{2+}$ influx, blockade of L-type channel completely blunted the light-induced OCR (Fig. 11). Importantly, optogenetic activation of $\mathrm{Ca}^{2+}$ cycling was sufficient to stimulate glucose oxidation in ChR2-expressing beige adipocytes, but not in control cells (Fig. $1 \mathrm{~m}$ ).

Optogenetics device stimulates fat thermogenesis via SERCA2. We next determined if this system sufficiently enhanced adipose tissue thermogenesis in vivo. To do this, we generated AdipoChR2 mice that expressed ChR2 selectively in mature adipocytes by crossing Adiponectin-Cre mice with Ai32 mice that expressed an improved ChR2 protein (ChR2 H134R) fused to EYFP only in Cre-expressing cells (Supplementary Fig. 2a). Following implantation of the wireless optogenetics devices into the inguinal WAT of Adipo-ChR2 or littermate control mice, we monitored changes in the adipose tissue temperature using the micro-temperature probes (Fig. 2a). During the temperature recording, we needed to keep the temperature probe within the inguinal adipose tissue. As such, the inguinal adipose tissue lost some insulation (i.e., the fur and skin), resulting in a modest reduction in adipose tissue temperatures of control mice. In contrast, optogenetic activation of ChR2 potently increased the inguinal WAT temperature of
Adipo-ChR2 mice (Fig. 2b). Notably, the light-stimulated adipose tissue thermogenesis occurred selectively in the inguinal WAT and lasted for approximately $70 \mathrm{~min}$ even after the end of light stimulation, although the duration would include both thermogenesis and heat retention (Fig. $2 c$ and Supplementary Fig. 2b).

Our previous study shows that $\mathrm{Ca}^{2+}$ cycling thermogenesis is an ATP-dependent process in beige fat, and is near completely absent in interscapular BAT (iBAT) ${ }^{10}$. We reasoned that brown adipocytes express low levels of the ATP synthase and thus possess low ATP synthesis capacity ${ }^{5,18}$. Hence, we examined the tissue specificity of light-activated thermogenesis in iBAT. To this end, we implanted the wireless optogenetic device into the interscapular region of Adipo-ChR2 mice and control mice. Subsequently, we monitored temperature changes in the iBAT in response to light activation of ChR2 (Supplementary Fig. 2c). We found that optogenetic activation of ChR2 in the interscapular region did not trigger thermogenesis in the iBAT (Supplementary Fig. 2d), suggesting that light-activated thermogenesis is selective to the subcutaneous WAT.

Next, we examined if optogenetic activation of ChR2 triggers intracellular $\mathrm{Ca}^{2+}$ influx in Ucp1 null adipocytes because $\mathrm{Ca}^{2+}$ cycling in beige adipocytes occurs independently of UCP $1^{10}$. We found that the optimized light-pulses potently increased intracellular $\mathrm{Ca}^{2+}$ influx in Ucp1 null beige adipocytes to a similar degree to wild-type cells expressing ChR2 (Fig. 2d and Supplementary Fig. 2e, f). In contrast, the optogenetic stimulation with the same frequency and width completely failed to alter intracellular $\mathrm{Ca}^{2+}$ influx in SERCA2-depleted adipocytes (Fig. 2d). Consistent with the results, NA stimulated intracellular $\mathrm{Ca}^{2+}$ influx in wild-type and Ucp1 null beige adipocytes, whereas NA failed to do so in SERCA2-depleted adipocytes (Supplementary Fig. 3a). This increase in $\mathrm{Ca}^{2+}$ flux was accompanied by increased OCR in wild-type and Ucp1 null beige adipocytes but not in SERCA2-depleted adipocytes (Supplementary Fig. 3b). Together, these data suggest that optogenetic activation of ChR2 triggers $\mathrm{Ca}^{2+}$ cycling through SERCA2 in a UCP1-independent manner.

As an alternative approach to stimulate light-activated fat thermogenesis, we delivered the adeno-associated virus (AAV) expressing ChR2 or GFP control into the inguinal WAT. To further determine the requirement of $\mathrm{Ca}^{2+}$ cycling for lightactivated thermogenesis, we expressed ChR2 in Adipocytespecific Serca2 KO mice that we generated in our previous study $^{10}$ (Fig. 2e, f). Consistent with the results in Adipo-ChR2 mice, optogenetic activation of $\mathrm{ChR} 2$ potently stimulated thermogenesis in the inguinal WAT expressing AAV-mediated ChR2. However, the light-activated thermogenesis was completely abrogated in the inguinal WAT of Adipo-Serca2 $\mathrm{KO}$ mice 
a

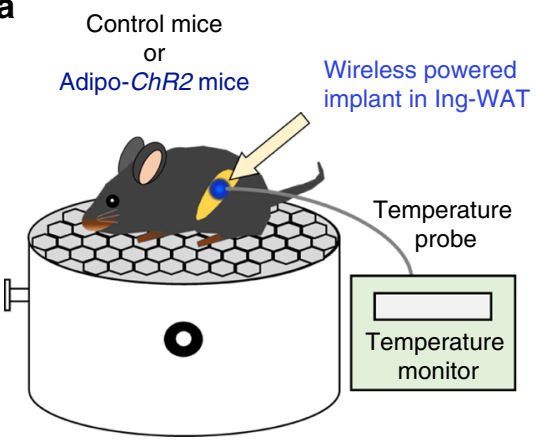

b

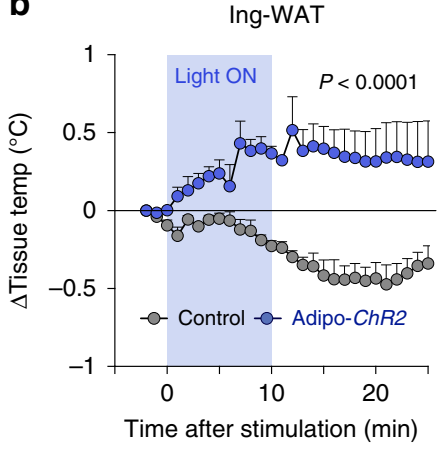

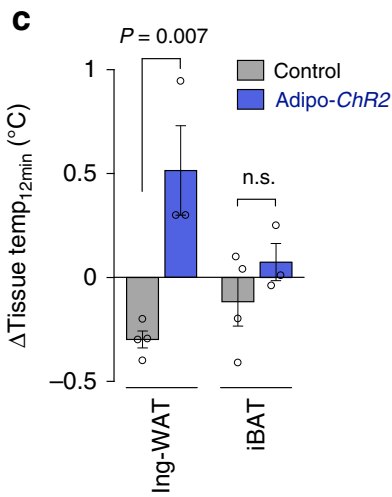

d
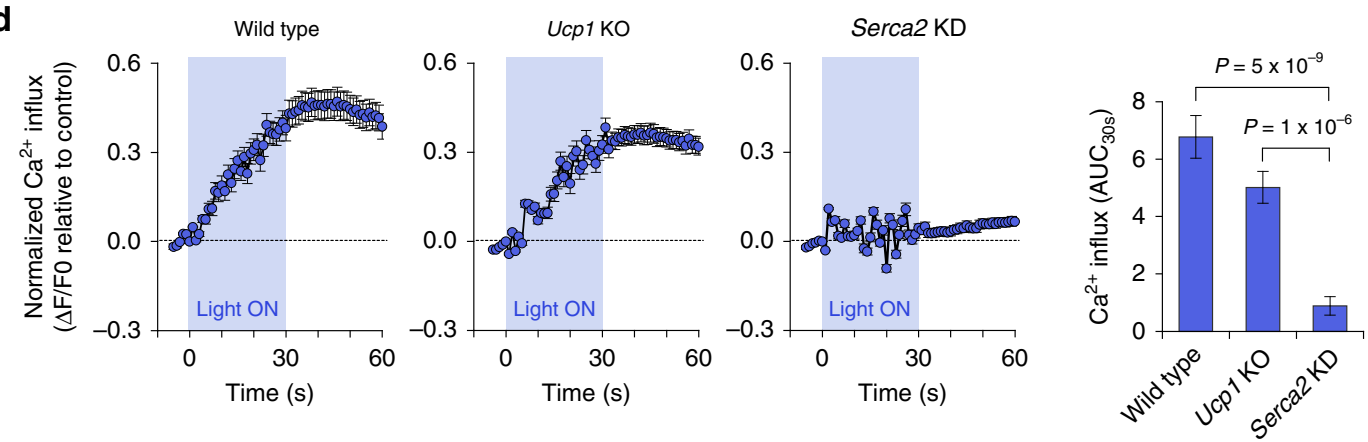

e

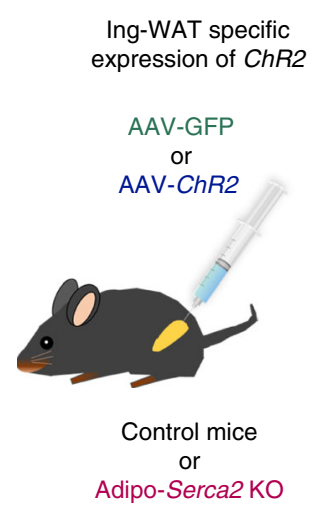

f

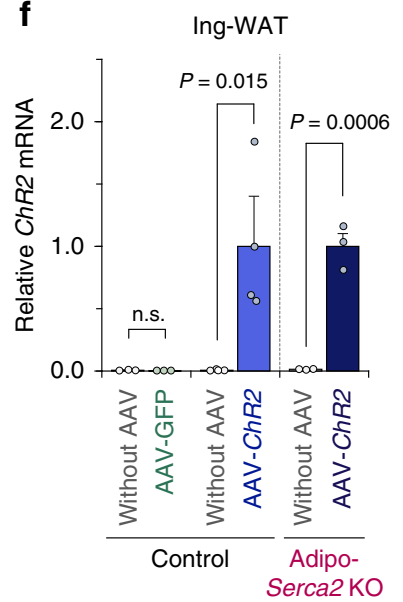

g

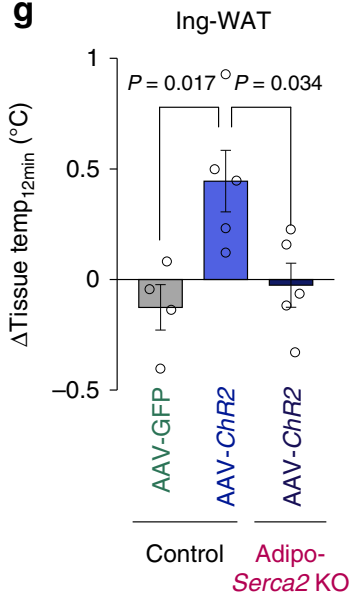

Fig. 2 Wireless optogenetics stimulates $\mathbf{C a}^{2+}$ cycling fat thermogenesis through SERCA2. a Schematic illustration of the tissue temperature recording in device-implanted mice. $\mathbf{b}$ Real-time changes in the inguinal WAT temperature of Adipo-ChR2 mice and littermate controls following optogenetic stimulation. Control, $n=4$; Adipo-ChR2, $n=3$. c Quantification of light-induced thermogenesis in the inguinal WAT and iBAT of Adipo-ChR2 mice and littermate controls in $\mathbf{b}$. Control, $n=4$; Adipo-ChR2, $\mathrm{n}=3$. d Real-time changes in intracellular $\mathrm{Ca}^{2+}$ influx in wild-type, Ucp1 KO, and Serca2KD beige adipocytes following optogenetics light stimulation. Wild-type, $n=134$ for both groups; Ucp1 KO control, $n=140 ;$ Ucp1 KO-ChR2, $n=139 ;$ Serca2KD control, $n=139$; Serca2KD-ChR2, $n=134$. e Schematic illustration of the experiment. AAV-GFP or AAV-ChR2 were injected into the inguinal WAT of Adipo-Serca2 $\mathrm{KO}$ and age-matched control mice. $\mathbf{m}$ mNA expression of ChR2 in the left side (with AAV) and the right side (without AAV) of inguinal WAT. mRNA expression was normalized to 36B4. Control with AAV-GFP, $n=3$ for with or without AAV; Control with AAV-ChR2, $n=4$ for with or without AAV; Adipo-Serca2 KO with AAV-ChR2, $n=3$ for with or without AAV. $\mathbf{g}$ Quantification of light-stimulated thermogenesis in the inguinal WAT of mice in f. Control with AAV-GFP, $n=4$; Control with AAV-ChR2, $n=5$; Adipo- Serca2 KO with AAV-ChR2, $n=5$. Data were analyzed by two-way repeated measures ANOVA (b), unpaired two-sided t-test $(\mathbf{c}, \mathbf{f})$, or two-way ANOVA (d) or one-way ANOVA (g) by Tukey's post hoc test. All Data are expressed as means \pm s.e.m. n.s. not significant.

that expressed ChR2 (Fig. 2g). No change was detected in the skeletal muscle temperature of all the mice (Supplementary Fig. 3c). Together, these results suggest that optogenetic activation of ChR2 triggers adipose tissue thermogenesis in vivo, and that this effect requires $\mathrm{Ca}^{2+}$ cycling through SERCA2 and RyR2/IP ${ }_{3}$.
Optogenetics device increases whole-body energy expenditure. Next, we asked if optogenetic activation of beige fat thermogenesis could lead to an increase in whole-body energy expenditure without external cold stimuli. To this end, we implanted the wireless optogenetic device into control and Adipo-ChR2 mice under a thermoneutral condition at $30^{\circ} \mathrm{C}$, where the 

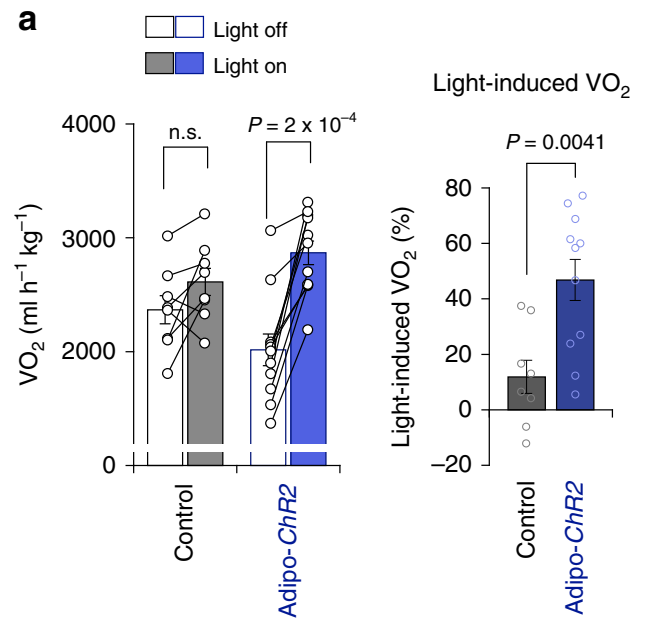

b
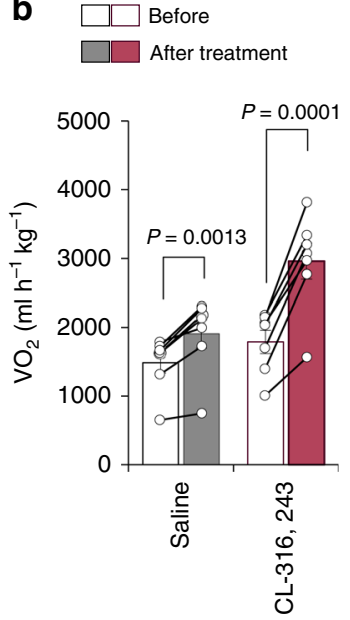

CL-induced $\mathrm{VO}_{2}$

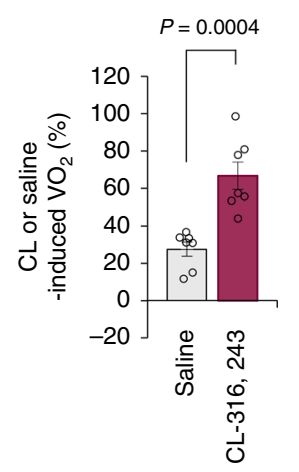

Fig. 3 Wireless optogenetics increases whole-body energy expenditure at thermoneutrality. a Whole-body oxygen consumption rate $\left(\mathrm{VO}_{2}\right)$ of $A d i p o-$ ChR2 mice and littermate controls following optogenetics light stimulation at thermoneutrality (left). The quantification of light-stimulated $\mathrm{VO}_{2}$ is shown on the right graph. Control, $n=8$; Adipo-ChR2, $n=11$. b Whole-body $\mathrm{VO}_{2}$ following a single administration of $\beta 3$ adrenergic receptor agonist (CL-316,243 at $0.01 \mathrm{mg} \mathrm{kg}^{-1}$ ) or vehicle (saline) at thermoneutrality. The quantification of CL-316,243 or saline-induced $\mathrm{VO}_{2}$ of wild-type mice is shown on the right. saline, $n=7 ; \mathrm{CL}-316,243, n=7$. Data were analyzed by two-way repeated-measures ANOVA followed by post-hoc paired/unpaired $t$-test with Bonferroni's correction (left in a-b) or unpaired two-sided t-test (right in a-b). All Data are expressed as means \pm s.e.m. n.s. not significant.

SNS-mediated regulation of thermogenesis was minimized. Subsequently, we measured whole-body oxygen consumption rate $\left(\mathrm{VO}_{2}\right)$ of control and Adipo-ChR2 mice during 30 min before and after a 10 -min optogenetic stimulation. We found that optogenetic stimulation of fat thermogenesis significantly increased $\mathrm{VO}_{2}$ of Adipo-ChR2 mice by $34.9 \%$ relative to control mice (Fig. 3a). During the metabolic cage studies, we did not detect any difference in the locomotor activity between control and Adipo-ChR2 mice (Supplementary Fig. 3d). These results suggest that the increase in whole-body energy expenditure stems from enhanced thermogenesis in the inguinal WAT. Notably, this increase in whole-body energy expenditure by a 10-min optogenetic stimulation was equivalent to the effect seen after a single administration of $\beta 3-\mathrm{AR}$ agonist (CL-316,243) at the dose of $0.01 \mathrm{mg} \mathrm{kg}^{-1}$ in mice under the same thermoneutral condition: a single administration of CL-316,243 increased $\mathrm{VO}_{2}$ by $39.3 \%$ relative to mice received a saline injection at $30^{\circ} \mathrm{C}$ (Fig. $3 \mathrm{~b}$ ).

Light-activated thermogenesis protects against diet-induced obesity. The above results motivated us to test the hypothesis that optogenetic stimulation of adipose tissue thermogenesis protects against diet-induced obesity. Our data suggest that the lightinduced $\mathrm{Ca}^{2+}$ cycling thermogenesis requires SERCA2; however, the expression of SERCA2 in the adipose tissue decreases under an obese state ${ }^{10}$. Thus, control and Adipo-ChR2 mice received $\beta 3$-agonist treatment for 5 days prior to high-fat diet studies to induce SERCA2 expression in the inguinal WAT (Supplementary Fig. 4a). Subsequently, wireless optogenetic devices were implanted into the inguinal WAT of these mice. Five days following the device implantation, both control and Adipo-ChR2 groups received $10 \mathrm{~min}$ light pulses with $10-\mathrm{Hz}$ frequency and 5ms pulse width once a day for 23 days on a high-fat diet $(60 \%$ HFD). We found that Adipo-ChR2 mice gained significantly less body-weight than control mice at 4 days and thereafter following light-activated thermogenesis on a HFD $(P=0.0097$ by two-way ANOVA followed by unpaired two-sided $t$-test). At the end of the HFD experiments, Adipo-ChR2 mice gained significantly less body-weight than control mice by $2.6 \mathrm{~g}$ on average ( $9.6 \%$ bodyweight loss relative to controls) (Fig. 4a). During the study, no significant difference was detected in the food intake between the two groups (Fig. 4b).

The light-induced changes in body-weight were due to reduced fat mass in Adipo-ChR2 mice, but not to changes in lean mass (Fig. 4c). Specifically, the inguinal WAT of Adipo-ChR2 mice was significantly smaller than that of control mice at the end of HFD studies (Fig. 4d). A similar trend was seen in the epididymal WAT mass, while no change was noted in the iBAT and liver weight. Histological analyses found that the inguinal WAT of Adipo-ChR2 mice contained significantly smaller adipocytes than control mice (Fig. 4e, f). Since beige fat biogenesis is associated with reduced adipose tissue inflammation and fibrosis formation $^{19-21}$, we examined if light-activation of thermogenesis in the inguinal WAT altered the cellular composition of adipocytes as well as inflammatory and fibrotic cells. However, transcriptional analysis of the inguinal WAT of control and Adipo-ChR2 mice found no significant difference in the expression of genes involving in adipose tissue inflammation, fibrosis, and beige fat biogenesis (Supplementary Fig. 4b-d). Of note, device implantation did not alter the expression of pro-inflammatory genes in the inguinal WAT relative to sham-operated mice (Supplementary Fig. 4e). Because our metabolic study was limited to 4 weeks of HFD, mice did not develop notable glucose intolerance at the end of the HFD study. Similarly, hepatic triglyceride levels remained within a normal range. Thus, we did not find a significant difference in systemic glucose tolerance and hepatic triglyceride contents between control mice and Adipo-ChR2 mice at the end of HFD studies (Supplementary Fig. 4f, g).

\section{Discussion}

Emerging evidence suggests the importance of beige fat in the regulation of energy homeostasis, while its relative contribution to whole-body energy metabolism has been a topic of debate $e^{5,22}$. This is mainly because accurate estimation of beige fat's contribution relative to other tissues, such as skeletal muscle and BAT, is challenging when animals are exposed to external stimuli (e.g., cold) or hormonal cues (e.g., NA). In this regard, the wireless optogenetic technology enabled us to selectively stimulate ChR2-expressing adipocytes in the subcutaneous WAT of mice. Notably, our data suggest that a 10 -min stimulation of $\mathrm{Ca}^{2+}$ 

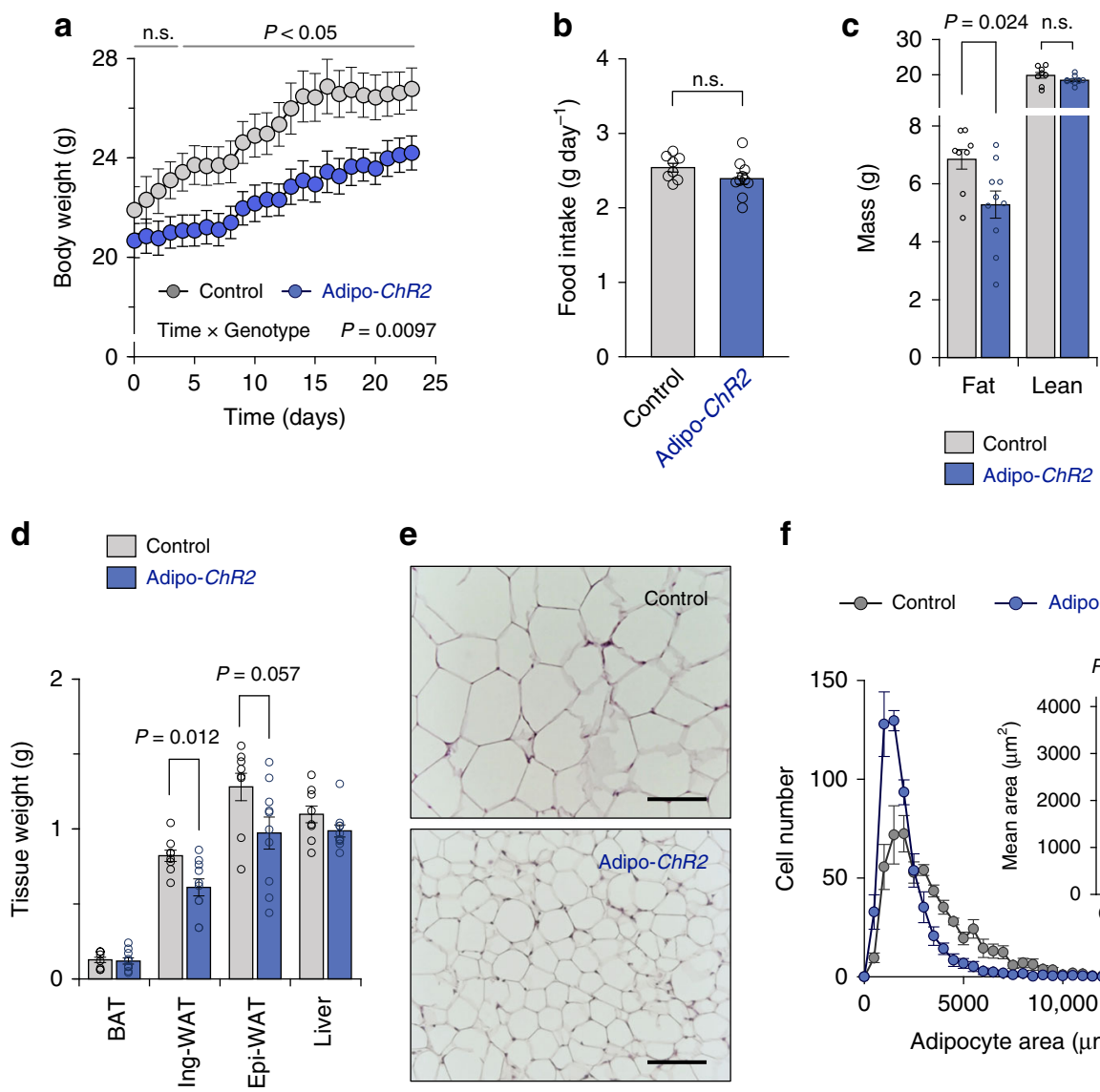

f

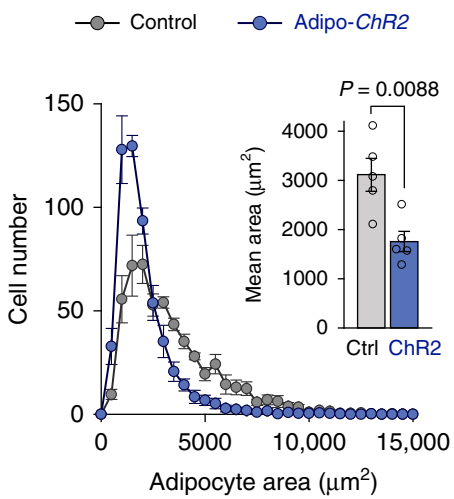

Fig. 4 Light-induced adipose tissue thermogenesis prevents diet-induced obesity. a Changes in body weight of Adipo-ChR2 mice and littermate controls. Control, $n=8$; Adipo-ChR2, $n=10$. b Food intake of Adipo-ChR2 mice and littermate control mice in a. Control, $n=8$; Adipo-ChR2 $n=10$. c Body composition of Adipo-ChR2 mice and littermate controls in a. Control, $n=8$; Adipo-ChR2, $n=10$. d Tissue-weight of adipose tissues and liver of AdipoChR2 mice and littermate controls in a. Control, $n=8$; Adipo-ChR2, $n=10$. e Representative images of hematoxylin and eosin (H\&E) staining of the inguinal WAT from Adipo-ChR2 mice (lower panel) and the littermate controls (upper panel). Scale bars,100 $\mu$ m. $\mathbf{f}$ Histogram (left panel) and quantification (right panel) of adipocyte size in the inguinal WAT in e. Control, $n=5$; Adipo-ChR2, $n=5$. Data were analyzed by two-way repeated-measures ANOVA followed by post hoc unpaired $t$-test with Bonferroni's correction (a), unpaired two-sided $t$-test (b-d, and $\mathbf{f}$ ). All data are expressed as means \pm s.e.m. n.s. not significant.

cycling thermogenesis per day, i.e., fat-specific "cold-mimetics", potently increased total energy expenditure of adult mice by $\sim 35 \%$ under a thermoneutral condition. This effect was substantial and was equivalent to the effect of a single administration of $\beta 3$-AR agonist, CL-316,243, at a dose of $0.01 \mathrm{mg} \mathrm{kg}^{-1}$ on total energy expenditure at thermoneutrality. Given the difference in body size/composition and pharmacokinetics between mice and humans, the above estimation cannot be translated directly to adult humans; however, a recent study in humans demonstrates that oral administration of mirabegron, a FDA-approved $\beta 3$-AR selective agonist, at $200 \mathrm{mg}$ increased resting metabolic rate by $\sim 200 \mathrm{kcal}^{7}$. According to a weight-loss prediction model in humans, every $100 \mathrm{~kJ}(23.9 \mathrm{kcal})$ per day increment of energy expenditure would lead to an eventual $1 \mathrm{~kg}$ body weight change with half of the predicted weight change in one year (i.e., $\sim 4 \mathrm{~kg}$ for $200 \mathrm{kcal} \mathrm{day}^{-1}$ increase) and $95 \%$ of the change in 3 years ${ }^{23}$.

Our data suggest that light-activation of ChR2 triggers $\mathrm{Ca}^{2+}$ release from the ER via RyR2 and $I_{3} R$, which leads to $\mathrm{Ca}^{2+}$ cycling and increased ATP consumption by SERCA2. Mechanistically, previous studies in SERCA1 (the muscle form of SERCA) reported that thermogenesis occurs when $\mathrm{Ca}^{2+}$ transport is uncoupled from ATP hydrolysis by SERCA1 under certain conditions, such as low ADP/ATP ratio or low $\mathrm{Ca}^{2+}$ binding affinity of SERCA (i.e., uncoupling of ATP hydrolysis and $\mathrm{Ca}^{2+}$ transport). When a $\mathrm{Ca}^{2+}$ gradient is formed across the ER or SR membrane, heat generation by the uncoupled SERCA1's ATPase activity can be up to $24.7 \mathrm{kcal} / \mathrm{ATP} \mathrm{mol}^{24,25}$. Mechanistically, it has been demonstrated that micropeptides, such as Phospholamban, Sarcolipin, DWORF, Myoregulin, control the $\mathrm{Ca}^{2+}$ affinity of SERCA in cardiac muscle and skeletal muscle ${ }^{26-30}$; among them, only sarcolipin has been shown to have the SERCA uncoupling activity. However, our RNA-seq data in beige adipocytes of mice and humans did not detect any of these micropeptides are expressed in beige adipocytes ${ }^{31}$. Thus, we aim to search for as-of-yet unknown regulators of SERCA2b ATPhydrolysis activity in beige adipocytes.

It is notable that optogenetic activation of ChR2 triggers a sustained increase in $\mathrm{Ca}^{2+}$ cycling thermogenesis in beige fat. It has been known that activation of L-type channel or changes in $\mathrm{ER} \mathrm{Ca}^{2+}$ concentration triggers $\mathrm{Ca}^{2+}$ release via $\mathrm{RyR} 2$ and IP3R $32-34$. Also, we found that RyR2 overexpression significantly increased UCP1-independent thermogenesis following NA treatment, whereas blockade of RyR2 and IP3R attenuates lightevoked intracellular $\mathrm{Ca}^{2+}$ flux and UCP1-independent thermogenesis ${ }^{10}$. Hence, it is conceivable that enhanced $\mathrm{ER} \mathrm{Ca}{ }^{2+}$ release via RyR2/IP3R significantly contributes to the sustained $\mathrm{Ca}^{2+}$ cycling thermogenesis through several mechanisms. For instance, PKA signaling, a major downstream signal of $\beta 3-\mathrm{AR}$, is known to phosphorylate RyR2, leading to enhanced $\mathrm{Ca}^{2+}$ release ${ }^{35}$. In addition, the cluster size of RyR2 controls $\mathrm{Ca}^{2+}$ release in smooth 
muscle cells ${ }^{36}$. Thus, future studies need to determine the mechanisms through which light- or NA-stimulation alters the open state of RyR2 and/or IP3R in adipocytes, such as timedependent changes in the phosphorylation and the cluster size.

In contrast to previous efforts to manipulate neural activities, the present study stimulated adipocytes by the wireless optogenetic device. A current technical limitation, however, is that the device is stable in the adipose tissue for up to 4 weeks in vivo. An improved optogenetic device with a longer period of high-fat diet study would warrant future studies to test the effect of lightactivated adipose tissue thermogenesis on systemic glucose homeostasis, insulin sensitivity, and hepatic steatosis. To this end, better encapsulation techniques should be applied to extend the longevity of the device. Besides, we may further smooth out the $\mathrm{PCB}$ corners and submerge the implant into epoxy in order to have a homogeneous thickness of insulation around the implants. Future designs on the device will also allow for temperature sensing and power control to minimize the heat emission from the device, such that light pulses of higher duty cycles can be applied to enhance $\mathrm{Ca}^{2+}$ cycling thermogenesis.

\section{Methods}

Wireless optogenetics device. The wireless optogenetics device consists of two main parts. The first part is a 2 -turn power receiving coil (2-mm diameter) made of copper wire (200- $\mu \mathrm{m}$ diameter). It extracts RF energy coupled from the cavity to the mouse in the in vivo experiments. The second part is the rectifier and microLED. The rectifier converts the RF energy into direct current to drive the microLED. It was implemented as a two-stage voltage doubling circuit using Schottky diodes (Skyworks, SMS7630-061). The micro-LED (Cree, DA2432) is in bare die form to save space. All components were bonded to a circuit board made of Rogers Printed Circuit Board (PCB) material for ease of cutting. The dimension of the circuit board is 1.6 by $1.8 \mathrm{~mm}$. The overall height of the implant is dominated by the height of the capacitors, which are $0.3 \mathrm{~mm}$. The entire device was encapsulated in epoxy and coated by Parylene- $\mathrm{C}$ to form a biocompatible and impermeable membrane protecting the internal electronics. Parylene-C was deposited using an SCS Labcoater 2 to a thickness of $2 \mu \mathrm{m}$ to ensure pinhole-free films. A 3-(trimethoxysilyl) propyl methacrylate (A-174 Silane) solution was used as an adhesion promoter to maximize the adhesion of the film to the surface of the device. To estimate the accelerated rate test of the wireless LED device, we simulated degradation of the implants using reactive accelerated aging (RAA) techniques ${ }^{37}$. Briefly, the implants were soaked into a solution of $20 \mathrm{mM}$ hydrogen peroxide $\mathrm{H}_{2} \mathrm{O}_{2}$ in Phosphate Buffer Saline (PBS) and were heated up to $60^{\circ} \mathrm{C}$, which mimics an immune system attack with accelerated reactive oxygen species (ROS) chemical reaction ${ }^{38}$. We refreshed the solution with additional $\mathrm{H}_{2} \mathrm{O}_{2}$ every $11 \mathrm{~h}$ for 5 days in order to maintain proper chemical reactions. At the end of the experiment, the implants were inspected under a microscope. To determine the light attenuation in adipose tissue, we measured the transmission of $470 \mathrm{~nm}$ light from the CREE micro-LED in freshly isolated adipose tissues (inguinal and epididymal WAT) and the brain of mice using a Thorlabs PM100D optical power meter. Tissues were placed between two glass slides, and the thickness was measured using a caliper. Transmission percentages were calculated as a ratio of the optical power measured through $2 \mathrm{~mm}$ of tissue or an air gap, to the power measured directly through the glass slides with no air gap. Based on the measurement of the attenuation coefficient in adipose tissues and a previous report showing that the threshold of stimulation for ChR2 is approximately $1 \mathrm{~mW} \mathrm{~mm}^{-239}$, it is estimated that the wireless LED device can stimulate ChR2-expressing cells in a surrounding region with a radius greater than $0.75 \mathrm{~mm}$, a broader area of adipose tissues relative to the brain.

Optogenetics device for cultured cells. A board with 24 LED's was fabricated to enable optogenetic testing with a seahorse cell culture plate. Blue LED's (BIVAR R20BLU-4-0045) were used, which have a peak wavelength of $470 \mathrm{~nm}$, and a typical luminous intensity of $8000 \mathrm{mcd}$. The LED's were soldered on a prototyping board, in series with a $47-\mathrm{Ohm}$ resistor to limit current. One LED was aligned with the center of each well on the seahorse plate. 4-Volt supplies were used to power the LED's. An Arduino program was used to control the LED's, with a frequency of $10 \mathrm{~Hz}$ and a duty cycle of 50\%. 2N7000 MOSFET's were used as switches to selectively control the power to the LED's.

Animals. All animal experimental procedures were performed in compliance with all relevant ethical regulations applied to the use of small rodents. The animal protocol was approved by the UCSF Institutional Animal Care and Use Committee. For the generation of adipocyte-specific express channelrhodopsin-2 (Adipo-ChR2) mice, Ai32 (RCL-ChR2 (H134R) /EYFP) mice (male, Bl6 background) were obtained from the Jackson Laboratory (Stock No: 024109) and crossed to Adiponectin-Cre mice. We also used male adipocyte-specific Serca2 KO mice (Adipo-Serca $2 \mathrm{KO}$, Adiponection-Cre $\times$ Atp $2 a 2^{\text {flox/flox}}$ ) in the Bl6 background as described previously ${ }^{10}$. For metabolic cage studies, we obtained male Bl6 mice from the Jackson Laboratory (Stock No: 000664). All the mice had free access to food and water, $12 \mathrm{~h}$ light-dark cycles, and were caged at an ambient temperature of $22^{\circ} \mathrm{C}$ or thermoneutrality $\left(30^{\circ} \mathrm{C}\right)$. For the study of stimulation with optogenetic wireless implant on a high-fat diet, Adipo-ChR2 mice (8-9 weeks old, male) and the littermate control mice (male) were treated with $\beta 3$ adrenergic receptor agonist $\left(\mathrm{CL}-316,243\right.$ (Sigma)) at $1 \mathrm{mg} \mathrm{kg}^{-1}$ for 5 days prior to the implantation surgery to induce SERCA2 expression in the adipose tissue. The mice were implanted with optogenetic wireless devices on the bilateral inguinal adipose tissues under isoflurane anesthesia $(2-3 \%)$. Five days after the implantation, all the mice received light-pulses with $10-\mathrm{Hz}$ frequency and 5-ms pulse width for $10 \mathrm{~min}$ once a day on a high-fat diet (D12492, Research diet). In this protocol, we minimize handling stress, and no change in animal behavior and food intake was noted.

Tissue temperature recording. For tissue temperature recording, type $\mathrm{T}$ thermocouple probes and/or fiber optic temperature probe were implanted into the adipose tissue of mice under anesthesia (Urethane at $1.3 \mathrm{~g} \mathrm{~kg}^{-1}$ ). Device implantation was performed according to the procedures described in previous studies $^{10,40}$. Tissue temperature was recorded by TC-2000 Meter (Sable Systems International) or Reflex fiber signal conditioner (Neoptix). The Neoptix T1 fiber optic temperature probe has a response time of less than $500 \mathrm{~ms}$ and the size of the sensitive area is 300 microns in diameter. Temperature recording was initiated once tissue temperature was stabilized prior to light-pulses.

Metabolic analyses. Whole-body energy expenditure and locomotor activity (beam break counts) were measured by using a comprehensive lab animal monitoring system (CLAMS) (Columbus Instruments). For the study of stimulation with optogenetic wireless implants, devices were implanted into the inguinal WAT of Adipo-ChR2 mice and the littermate control mice before CLAMS analysis. Five days after the implantation, whole-body oxygen consumption rate $\left(\mathrm{VO}_{2}\right)$, locomotor activity, and food intake were monitored at thermoneutrality $\left(30^{\circ} \mathrm{C}\right)$ by CLAMS. During the study, $\mathrm{VO}_{2}$ was measured before and after optogenetic stimulation at $10 \mathrm{~Hz}$ with 5 -ms pulses for $10 \mathrm{~min}$. For the study of $\beta 3$-AR agonist (CL-316,243) administration, $\mathrm{VO}_{2}$ was measured before and after a single injection with CL-316,243 at $0.01 \mathrm{mg} \mathrm{kg}^{-1}$ or saline in wild-type mice at 14-16 weeks old at thermoneutrality $\left(30^{\circ} \mathrm{C}\right)$. The measurement was the average values of $\mathrm{VO}_{2}$ for $30 \mathrm{~min}$ before and after optogenetic stimulation or a i.p. injection of CL-316,243 or saline. Fat mass and lean mass were measured by Body Composition Analyzer EchoMRI (Echo Medical Systems). For glucose tolerance test experiments, after $6 \mathrm{~h}$ of fasting, the mice were injected intraperitoneally with glucose $\left(2.0 \mathrm{~g} \mathrm{~kg}^{-1}\right)$. To measure liver triglyceride contents, liver tissues were homogenized in $350 \mu \mathrm{l}$ ethanolic $\mathrm{KOH}(100 \% \mathrm{EtOH}: 30 \% \mathrm{KOH}=2: 1)$ and incubated at $55^{\circ} \mathrm{C}$ overnight. Subsequently, tissue lysates were brought volume to $1 \mathrm{ml}$ with $50 \% \mathrm{EtOH}$. After centrifugation, the supernatant was incubated with $1 \mathrm{M} \mathrm{MgCl}_{2}$ on ice for $10 \mathrm{~min}$. Amounts of triglycerides were determined by an Infinity Triglycerides kit (Thermo).

Administration of AAV vectors. Adipo-Serca2 KO mice (14-18 weeks old) and age-matched wild-type mice were treated with $\beta 3$ adrenergic receptor agonist (CL316,243 ) at $1 \mathrm{mg} \mathrm{kg}^{-1}$ for 5 days. Subsequently, AAV expressing ChR2 (AAV8EF1a-hChR2 (H134R)-EYFP; the Neuroscience Gene Vector and Virus Core of Stanford University) or control GFP (AAV8-CAG-EGFP) were injected into the inguinal WAT of mice (viral titer: $8.5 \times 10^{9} \mathrm{GC}$ per mice). AAV was injected to six locations in the inguinal WAT to equally distribute the expression of ChR2 or GFP

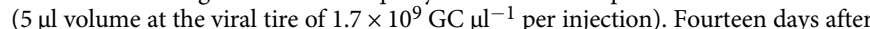
the AAV injection, tissue temperature was recorded in response to optogenetic light pulses. After temperature recording, the expression of ChR 2 was confirmed by measuring the mRNA expression by qRT-PCR.

Virus construction. Lentiviral vectors were obtained from Add-gene (pLentiEF1a-hChR2(H134R)-EYFP-WPRE, Catalog \#20942) and GeneCopoeia (shRNA targeting Atp2a2, CS-MSH028715-33-LVRU6GH; scrambled control, CSHCTR001-LVRU6GH). HEK293T cells were seeded at 70,000 cells per $\mathrm{cm}^{2}$ in $15 \mathrm{~cm}$ tissue culture dishes in $20 \mathrm{ml}$ media (DMEM, 10\% FBS) and incubated overnight at $37^{\circ} \mathrm{C}$ and $5 \% \mathrm{CO}_{2}$. Twenty-four hours after cell plating, $12 \mu \mathrm{g}$ of lentiviral transfer vector was transfected together with $7 \mu \mathrm{g}$ psPAX2 (Addgene $\# 12260$ ) and $3 \mu \mathrm{g}$ pMD2.G (Addgene \#12259) using $50 \mu \mathrm{l}$ jetPRIME transfection reagent (Polyplus). Seventy-two hours after transfection, cell culture media were collected and filtered. Lentivirus purification was performed at UCSF Viral Core. Beige adipocytes were incubated in the virus overnight in the medium containing $6 \mu \mathrm{g} \mathrm{ml}^{-1}$ polybrene. Blasticidin at $10 \mu \mathrm{g} \mathrm{ml}^{-1}$ or hygromycin at $200 \mu \mathrm{g} \mathrm{ml}^{-1}$ was used for selection.

Cell culture. Ucp1 KO beige adipocytes were generated by immortalizing the stromal vascular fraction (SVF) from the inguinal WAT of Prdm16 Tg x Ucp1 KO mice $^{10}$. SERCA2-depleted beige adipocytes were generated by infecting lentiviral shRNA targeting mouse Atp2a2 (CS-MSH028715-33-LVRU6GH) to immortalized 
beige adipocytes in our previous study ${ }^{10}$. Beige adipocyte differentiation was induced by treating confluent preadipocytes with DMEM containing $10 \%$ FBS, 0.5 $\mathrm{mM}$ isobutylmethylxanthine, $125 \mathrm{nM}$ indomethacin, $2 \mu \mathrm{g} \mathrm{ml}^{-1}$ dexamethasone, $850 \mathrm{nM}$ insulin, and $1 \mathrm{nM} \mathrm{T} 3$, and $0.5 \mu \mathrm{M}$ rosiglitazone ${ }^{41}$. Two days after induction, cells were switched to a maintenance medium containing $10 \%$ FBS, $850 \mathrm{nM}$ insulin, $1 \mathrm{nM} \mathrm{T} 3$, and $0.5 \mu \mathrm{M}$ rosiglitazone.

Intracellular $\mathbf{C a}^{2}+$ flux assays. Wild-type, Ucp1 KO, and Serca2-depleted beige adipocytes expressing vector or $C h R 2$ were differentiated on collagen-coated glassbottom dishes according to the beige fat differentiation protocol ${ }^{41}$. Intercellular $\mathrm{Ca}^{2}$ + levels were determined by using the Fluo-8 No Wash Calcium Assay kit (Abcam, ab112129). Differentiated adipocytes were incubated with Fluo-8 in calcium-free Hanks' balanced salt solution (HHBS) at $37^{\circ} \mathrm{C}$ for $30 \mathrm{~min}$ and subsequently incubated at room temperature for an additional $30 \mathrm{~min}$. Subsequently, the buffer was replaced by HHBS, including $1 \mathrm{mM} \mathrm{CaCl}$, followed by the intracellular $\mathrm{Ca}^{2+}$ flux assays. For experiments using $\mathrm{Ca}^{2+}$ channel inhibitors, differentiated beige adipocytes expressing $\mathrm{ChR} 2$ were incubated with $\mathrm{L}$-type $\mathrm{Ca}^{2+}$ channel blocker (isradipine at $10 \mu \mathrm{M}$ ), R-type $\mathrm{Ca}^{2+}$ channel blocker (SNX-482 at $100 \mathrm{nM}$ ), or Ttype $\mathrm{Ca}^{2+}$ channel blocker (NNC55-0396 at $3 \mu \mathrm{M}$ ), RyR2 receptor blocker (Ryanodine at $100 \mu \mathrm{M})$ or $\mathrm{IP}_{3} \mathrm{R}$ blocker $(2-\mathrm{APB}$ at $50 \mu \mathrm{M})$ for $90 \mathrm{~min}$ prior to optogenetics light stimulation. Intracellular $\mathrm{Ca}^{2+}$ level was monitored using a Revolve microscope (ECHO Laboratories) equipped with a $20 \times$ objective. The fluorescence was detected by the fluorescence filter Cube 2002 (ECHO Labolatories: Excitation $470 / 40 \mathrm{~nm}$, dichroic $495 \mathrm{~nm}$, emission 525/50 nm). Immediately after optogenetic light stimulation or adding noradrenaline at $1 \mu \mathrm{M}$, fluorescence intensity of differentiated adipocytes was monitored. Optogenetic light stimulation was delivered at $10 \mathrm{~Hz}$ with $5-\mathrm{ms}$ width for $30 \mathrm{~s}$. Image analyses were performed using the ImageJ software (https://imagej.nih.gov/ij/download.html). Specifically, the circular regions of interest (ROI) was placed onto individual differentiated adipocytes. Time-course changes in intracellular $\mathrm{Ca}^{2+}$ levels were recorded by quantifying the pixel intensity of the ROI and expressed as delta fluorescence ratio $F / F 0$ or delta $F / F 0$ relative to control, where $F$ is the fluorescence intensity at a given time and $F 0$ is the initial resting fluorescence intensity prior to stimuli. Background signal (signal from the area without cells) was subtracted from all data.

Cellular oxygen consumption assays (OCR). Oxygen consumption rate (OCR) in cultured adipocytes was measured using the Seahorse XFe Extracellular Flux Analyzer (Agilent) in a 24-well plate. For the measurement of NA-induced OCR, differentiated adipocytes were incubated in the XF assay media in the presence or absence of NA at $1 \mu \mathrm{M}$. For the measurement of optogenetics-induced cellular respiration, OCR in differentiated adipocytes expressing vector or ChR2 was measured in the XF assay media before and after optogenetics stimulation. Cells were stimulated with optogenetics light at $10 \mathrm{~Hz}$ with 50 -ms width for $10 \mathrm{~min}$ at $37{ }^{\circ} \mathrm{C}$. To inhibit L-type $\mathrm{Ca}^{2+}$ channel, cells were incubated with isradipine at $10 \mu \mathrm{M}$ or vehicle for $90 \mathrm{~min}$ prior to light stimulation. Light-induced OCR (\%) values were calculated by OCR after light stimulation normalized by basal OCR prior to light stimulation. The XF assay medium was supplemented with $1 \mathrm{mM}$ sodium pyruvate, $2 \mathrm{mM}$ GlutaMax ${ }^{\mathrm{TM}}-\mathrm{I}$, and $25 \mathrm{mM}$ glucose.

Glucose oxidation. Differentiated adipocytes were incubated in DMEM containing $2 \% \mathrm{FBS}$ for $2 \mathrm{~h}$. After washing in PBS, cells were incubated in $1 \mathrm{ml}$ of KRB/HEPES buffer that contained $1.8 \mathrm{mM} \mathrm{CaCl}_{2}, 2 \% \mathrm{BSA}, 15 \mathrm{mM}$ glucose, $200 \mathrm{nM}$ adenosine, and $0.5 \mu \mathrm{Ci}\left[1-{ }^{14} \mathrm{C}\right]$ glucose. Cells received optogenetic light stimulation on a board with 24 LED's at $10 \mathrm{~Hz}$ with 50 -ms width for $30 \mathrm{~min}$ at $37^{\circ} \mathrm{C}$. Subsequently, $350 \mu \mathrm{l}$ of $30 \%$ hydrogen peroxide was added in each well, and $\left[{ }^{14} \mathrm{C}\right] \mathrm{CO}_{2}$ from each well was trapped in the smears supplemented with $300 \mu \mathrm{l}$ of $1 \mathrm{M}$ benzethonium hydroxide solution at room temperature for $20 \mathrm{~min}$. Glucose oxidation was quantified by counting the radioactivity of trapped $\left[{ }^{14} \mathrm{C}\right] \mathrm{CO}_{2}$ using a scintillation counter.

Histology. For hematoxylin and eosin (H\&E) staining, adipose tissues were fixed in $4 \%$ paraformaldehyde, followed by $70 \%$ ethanol. Tissues were embedded in paraffin, sectioned at $5 \mu \mathrm{m}$, and stained with $\mathrm{H} \& \mathrm{E}$. Adipocyte images were acquired using a Revolve microscope (ECHO Laboratories), and the cellular size was quantified by using the Image J software. For the adipocyte size quantification, we measured at least 500 cells per mouse.

Quantitative RT-PCR. Total RNA was extracted from the adipose tissues using RiboZol reagents (AMRESCO) followed by the RNeasy mini-kit (Qiagen Inc., Valencia, CA). cDNA was synthesized by iScript cDNA Synthesis kit (BioRad) according to the provided protocol. Quantitative real-time PCR (qRT-PCR) was performed using an ABI ViiA ${ }^{m}$ 7 PCR cycler (Applied Biosystems). Each sample was run in duplicate, and the expression levels of each gene were normalized to 36B4. Relative mRNA levels were determined by the $\Delta \Delta$ Ct method and normalized to an internal calibrator specific to each gene using the formula $2^{-\Delta \Delta C T}$. Primer sequences are provided in Supplementary Table 1.
Statistical analysis. Statistical analyses were performed using GraphPad Prism 7.0 (GraphPad Software, Inc., La Jolla, CA). All data are expressed as means \pm SEM. Comparisons between the two groups were analyzed using the paired or unpaired $t$-test as appropriate. One-way or two-way ANOVA, followed by Tukey's test was used for multiple group comparisons. Two-way repeated-measures ANOVA followed by post-hoc paired/unpaired $t$-test with Bonferroni's correction was used for the comparisons of repeated measurements. $P$ values below 0.05 were considered significant throughout the study.

\section{Data availability}

The source data underlying Figs. 1d-m, 2b-d, f, g, 3a, b, 4a-d, f, and Supplementary Figs. 1a, b, d-g, 2a, b, d-f, 3a-d, and 4a-g are provided as a Source Data file. All other relevant data of this study are available from the corresponding authors upon reasonable request. A reporting summary is available as a Supplementary Information file.

\section{Received: 6 September 2019; Accepted: 18 March 2020;}

Published online: 07 April 2020

\section{References}

1. Sidossis, L. \& Kajimura, S. Brown and beige fat in humans: thermogenic adipocytes that control energy and glucose homeostasis. J. Clin. Investig. 125, 478-486 (2015).

2. Harms, M. \& Seale, P. Brown and beige fat: development, function and therapeutic potential. Nat. Med. 19, 1252-1263 (2013).

3. Collins, S. beta-Adrenoceptor signaling networks in adipocytes for recruiting stored fat and energy expenditure. Front. Endocrinol. 2, 102 (2011).

4. Cannon, B. \& Nedergaard, J. Brown adipose tissue: function and physiological significance. Physiol. Rev. 84, 277-359 (2004).

5. Ikeda, K., Maretich, P. \& Kajimura, S. The common and distinct features of Brown and Beige adipocytes. Trends Endocrinol. Metab. 29, 191-200 (2018).

6. Chouchani, E. T., Kazak, L. \& Spiegelman, B. M. New advances in adaptive thermogenesis: UCP1 and beyond. Cell Metab. 29, 27-37 (2019).

7. Cypess, A. M. et al. Activation of human brown adipose tissue by a beta3adrenergic receptor agonist. Cell Metab. 21, 33-38 (2015).

8. Arch, J. R. Challenges in beta(3)-adrenoceptor agonist drug development. Ther. Adv. Endocrinol. Metab. 2, 59-64 (2011).

9. Cannavo, A. \& Koch, W. J. Targeting beta3-adrenergic receptors in the heart: selective agonism and beta-blockade. J. Cardiovasc. Pharm. 69, 71-78 (2017).

10. Ikeda, K. et al. UCP1-independent signaling involving SERCA2b-mediated calcium cycling regulates beige fat thermogenesis and systemic glucose homeostasis. Nat. Med. 23, 1454-1465 (2017).

11. Kazak, L. et al. A creatine-driven substrate cycle enhances energy expenditure and thermogenesis in beige fat. Cell 163, 643-655 (2015).

12. Montgomery, K. L. et al. Wirelessly powered, fully internal optogenetics for brain, spinal and peripheral circuits in mice. Nat. Methods 12, 969-974 (2015).

13. Ho, J. S. et al. Self-tracking energy transfer for neural stimulation in untethered mice. Phys. Rev. Appl. 4, 024001 (2015).

14. Yeh, A. J. et al. Wirelessly powering miniature implants for optogenetic stimulation. Appl. Phys. Lett. 103, 163701 (2013).

15. Nagel, G. et al. Channelrhodopsin-2, a directly light-gated cation-selective membrane channel. Proc. Natl Acad. Sci. USA 100, 13940-13945 (2003).

16. Altshuler-Keylin, $\mathrm{S}$. et al. Beige adipocyte maintenance is regulated by autophagy-induced mitochondrial clearance. Cell Metab. 24, 402-419 (2016)

17. Reinbothe, T. M., Safi, F., Axelsson, A. S., Mollet, I. G. \& Rosengren, A. H. Optogenetic control of insulin secretion in intact pancreatic islets with betacell-specific expression of Channelrhodopsin-2. Islets 6, e28095 (2014).

18. Kramarova, T. V. et al. Mitochondrial ATP synthase levels in brown adipose tissue are governed by the c-Fo subunit P1 isoform. FASEB J. 22, 55-63 (2008).

19. Hasegawa, Y. et al. Repression of adipose tissue fibrosis through a PRDM16GTF2IRD1 complex improves systemic glucose homeostasis. Cell Metab. 27, 180-194 e186 (2018).

20. Wang, W. et al. A PRDM16-driven metabolic signal from adipocytes regulates precursor cell fate. Cell Metab. 30, 174-189 e175 (2019).

21. Cohen, P. et al. Ablation of PRDM16 and beige adipose causes metabolic dysfunction and a subcutaneous to visceral fat switch. Cell 156, 304-316 (2014).

22. Chouchani, E. T. \& Kajimura, S. Metabolic adaptation and maladaptation in adipose tissue. Nat. Metab. 1, 189-200 (2019).

23. Hall, K. D. et al. Quantification of the effect of energy imbalance on bodyweight. Lancet 378, 826-837 (2011).

24. de Meis, L. Uncoupled ATPase activity and heat production by the sarcoplasmic reticulum Ca2+-ATPase. Regulation by ADP. J. Biol. Chem. 276, 25078-25087 (2001) 
25. de Meis, L. Brown adipose tissue Ca2+-ATPase: uncoupled ATP hydrolysis and thermogenic activity. J. Biol. Chem. 278, 41856-41861 (2003).

26. Odermatt, A. et al. Characterization of the gene encoding human sarcolipin (SLN), a proteolipid associated with SERCA1: absence of structural mutations in five patients with Brody disease. Genomics 45, 541-553 (1997).

27. Anderson, D. M. et al. A micropeptide encoded by a putative long noncoding RNA regulates muscle performance. Cell 160, 595-606 (2015).

28. Nelson, B. R. et al. A peptide encoded by a transcript annotated as long noncoding RNA enhances SERCA activity in muscle. Science 351, 271-275 (2016).

29. Anderson, D. M. et al. Widespread control of calcium signaling by a family of SERCA-inhibiting micropeptides. Sci. Signal. 9, ra119 (2016).

30. MacLennan, D. H. \& Kranias, E. G. Phospholamban: a crucial regulator of cardiac contractility. Nat. Rev. Mol. Cell Biol. 4, 566-577 (2003).

31. Shinoda, K. et al. Genetic and functional characterization of clonally derived adult human brown adipocytes. Nat. Med. 21, 389-394 (2015).

32. Lemmens, R., Larsson, O., Berggren, P. O. \& Islam, M. S. Ca2+-induced Ca2+ release from the endoplasmic reticulum amplifies the $\mathrm{Ca} 2+$ signal mediated by activation of voltage-gated L-type $\mathrm{Ca} 2+$ channels in pancreatic beta-cells. $J$. Biol. Chem. 276, 9971-9977 (2001).

33. Santulli, G., Nakashima, R., Yuan, Q. \& Marks, A. R. Intracellular calcium release channels: an update. J. Physiol. 595, 3041-3051 (2017).

34. Burdakov, D., Petersen, O. H. \& Verkhratsky, A. Intraluminal calcium as a primary regulator of endoplasmic reticulum function. Cell Calcium 38, 303-310 (2005).

35. Marx, S. O. et al. PKA phosphorylation dissociates FKBP12.6 from the calcium release channel (ryanodine receptor): defective regulation in failing hearts. Cell 101, 365-376 (2000)

36. Soeller, C. Ryanodine receptor cluster size sets the tone in cerebral smooth muscle. Proc. Natl Acad. Sci. USA 115, 10195-10197 (2018).

37. Kuliasha, C. A. \& Judy, J. W. In vitro reactive-accelerated-aging (RAA) assessment of tissue-engineered electronic nerve interfaces (TEENI). Conf. Proc. IEEE Eng. Med. Biol. Soc. 2018, 5061-5064 (2018).

38. Street, M. G., Welle, C. G. \& Takmakov, P. A. Automated reactive accelerated aging for rapid in vitro evaluation of neural implant performance. Rev. Sci. Instrum. 89, 094301 (2018).

39. Mohanty, S. K. \& Lakshminarayananan, V. Optical techniques in optogenetics. J. Mod. Opt. 62, 949-970 (2015).

40. Chen, Y. et al. Thermal stress induces glycolytic beige fat formation via a myogenic state. Nature 565, 180-185 (2019).

41. Ohno, H., Shinoda, K., Spiegelman, B. M. \& Kajimura, S. PPARgamma agonists induce a white-to-brown fat conversion through stabilization of PRDM16 protein. Cell Metab. 15, 395-404 (2012).

\section{Acknowledgements}

We are thankful to Dr. Karl Deisseroth at Stanford University for providing pAAVEF1a-hChR2(H134R)-EYFP and Dr. Chiristophe Paillart at UCSF for his support in the CLAMS study. We also thank Mr. Zachary Brown for editorial help. This work was supported by the NIH (DK97441) and the Edward Mallinckrodt Jr. Foundation to S.K. A.P. is a Chan Zuckerberg Biohub investigator. K.T. and Y.O. are supported by the Manpei Suzuki Diabetes Foundation, and T.Y. is supported by the Uehara Memorial Foundation. E.T. is supported by the T.J. Rodgers Stanford Graduate Fellowship.

\section{Author contributions}

K.T., K.I., Y.T., A.P., and S.K. conceived the study and designed experiments. K.T. and K.I. carried out overall cellular and mouse experiments and analyzed data. T.Y. assisted with mouse experiments and cultured cell studies and interpreted the data. Y.O. assisted with mouse experiments. Y.T., E.T., M.F., and A.P. designed, built, characterized the optogenetics device, performed the experiments about the device of efficiency, optical property, and degradation, and interpreted the data. K.T., K.I., A.P., and S.K. wrote the paper with input from all the authors.

\section{Competing interests}

The authors declare no competing interests.

\section{Additional information}

Supplementary information is available for this paper at https://doi.org/10.1038/s41467 020-15589-y.

Correspondence and requests for materials should be addressed to A.S.Y.P. or S.K.

Peer review information Nature Communications thanks the anonymous reviewer(s) for their contribution to the peer review of this work.

Reprints and permission information is available at http://www.nature.com/reprints

Publisher's note Springer Nature remains neutral with regard to jurisdictional claims in published maps and institutional affiliations.

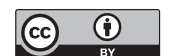

Open Access This article is licensed under a Creative Commons Attribution 4.0 International License, which permits use, sharing, adaptation, distribution and reproduction in any medium or format, as long as you give appropriate credit to the original author(s) and the source, provide a link to the Creative Commons license, and indicate if changes were made. The images or other third party material in this article are included in the article's Creative Commons license, unless indicated otherwise in a credit line to the material. If material is not included in the article's Creative Commons license and your intended use is not permitted by statutory regulation or exceeds the permitted use, you will need to obtain permission directly from the copyright holder. To view a copy of this license, visit http://creativecommons.org/ licenses/by/4.0/.

(C) The Author(s) 2020 